\title{
Occurrence of Natural Enemies of Fruit Flies in Mango Ecosystem
}

\author{
K.S. Ashoka ${ }^{1 *}$ and Javaregowda ${ }^{2}$ \\ ${ }^{1}$ Department of Agricultural Entomology, College of Agriculture, Dharwad-580005, India \\ ${ }^{2}$ Department of Forest Biology and Tree Improvement, College of Agriculture, \\ Dharwad-580005, India \\ *Corresponding author
}

\begin{tabular}{|l|}
\hline Ke y w o r d s \\
Natural enemies, \\
Bactrocera spp., \\
Braconidae, \\
Diapriidae, Mango \\
ecosystem etc.
\end{tabular}

A B S T R A C T
The work was carried out in the year 2018 from May to August on natural enemies of fruit flies viz., Bactrocera dorsalis (Hendel), Bactrocera zonata (Saunders), Bactrocera correcta (Bezzi) and Bactrocera caryeae (Kapoor) in mango ecosystem. The results of the studies indicated that among the natural enemies occurring on fruit flies. The mean per cent parasitism of Braconid parasitoid, Diachasmimorpha longicaudata species complex was an average mean (8.81) with highest per cent parasitism was found in the month of July (13.70) followed by June. The per cent parasitism of Diapriids was average mean (5.22) the highest per cent parasitism was found in the month of July (9.54) followed by August and no parasitism. There is no significance difference between the pooled mean of Braconid and Diapriidsparasitoid.

\section{Introduction}

India has nearly 200 species of fruit flies, which is about 5 per cent of known tephritid fauna of the world. In the family tephritidae, the subfamily dacinae has a maximum number of economically important species and the tribe dacini with the genus, Bactrocera is occurring more abundantly in India. From an economic point of view, Bactrocera dorsalis (Hendel), B. zonata (Saunders), B. correcta (Bezzi) and B. caryeae (Kapoor) are important
(Verghese et al., 2002). The important host plants of $B$. dorsalis and B. zonata are mango, guava, peach, citrus, pear, ber and loquat (Singh et al., 2016). Due to their polyphagous nature of feeding behaviour, they are gaining more importance in agriculture.

It is difficult to manage fruit fly simply through the application of chemicals since egg, maggot and pupal life stages are hidden in either in the fruits or in the soil. The present scenario warrants the need of integrated 
approach for eco-friendly management of fruit flies (Singh and Kaur, 2016) with more emphasis on biological approach as fruits harbouring these pests are mainly consumed raw. Hence, keeping these points in view present experiment was undertaken to study the natural parasitism in mango ecosystem.

\section{Materials and Methods}

The studies were carried out to understand natural enemies of fruit flies in mango ecosystem from April to August 2018. During mango fruiting season ten fallen fruits infested with fruit flies were collected and brought to the laboratory at weekly interval. The collected fruits were kept in rearing cages provided with a thin layer of sand for pupation. After the pupation, pupae were collected and kept in glass vails to observe for the emergence of natural enemies as well as fruit flies. After the emergence of natural enemies per cent parasitism was calculated by following formula:

Parasitism (\%)

Number of natural enemies emerged From fruit fly pupae kept for observation

=--------------------------------------------------×100

Total number of fruit fly pupae kept for observation

\section{Results and Discussion}

Results of the studies indicated that among the natural enemies occurring on fruit flies ( $B$. dorsalis, B. zonata, B.correcta and B.caryeae), the Braconid and Diapriid parasitoid, found through observation period (Table 1). Per cent parasitism of Diachasmimorpha longicaudata species complex belong to family Braconidae, ranged from 3.05 to 13.70 with an average mean of 8.81. The highest per cent parasitism was found in the month of July (13.70) followed by June (12.40), August (6.10), May (3.05) (Table 2 and Fig. 1). Similarly, the parasitoids Trichorpia sp., Spilomicrus manii and Copterabharatvarshus belong to family Diapriidae was found throughout the observation period from May to August 2018. The per cent parasitism of Diapriids ranged from 1.38 to 9.54 with an average mean of 5.22. The highest per cent parasitism was found in the month of July (9.54) followed by August (7.49), June (2.49), May (1.38) (Table 2 and Fig. 1).

Parasitoids are density defenders, the population are depended on the availability of host and fruiting season. The highest per cent parasitism of Braconidae and Diapriidae was found in the month of July (13.74 and 9.54) which can be attributed to ripening season of mango which leads to increased incidence of fruit fly.

The present findings are in line with findings of Mala (2013) and Singh (2016) noticed the occurrence of D. longicaudata (Ashmead) on Bactrocera spp. and B. caryeae (Kapoor) from Punjab and Kodagu (Karnataka) respectively. Laskar et al., (2017) observed that there was 33.47 per cent parasitism of Diachasmimorpha spp. on melon fruit fly and also they confirmed Diachasmimorpha spp. is a larval-pupal parasitoid. Aneeldev (2018) was observed in the period from May to October, 2017 ranging from 8.98 to 13.52 per cent parasitism of Diachasmimorpha spp. on Bactrocera spp. Ovruski et al., (2000) reported Diapriid Copterahaywardi in Argentina, Brazil, Venezuela and Mexico, while Trichopria anastrepha is present only in Brazil and Argentina. Aneeldev (2018) was observed in the period from May to October 2017 ranging from 2.20 to 10.82 per cent parasitism of Diapriids on Bactrocera spp (Fig. 2). 
Table.1 List of natural enemies' species recorded in mango ecosystem during fruiting period (May to August, 2018)

\begin{tabular}{|c|c|c|c|}
\hline $\begin{array}{c}\text { Sl. } \\
\text { No. }\end{array}$ & Parasitoid & Family & Order \\
\hline $\mathbf{1}$ & $\begin{array}{c}\text { Diachasmimorpha longicaudata } \\
\text { species complex (Ashmead) }\end{array}$ & Braconidae & Hymenoptera \\
\cline { 1 - 2 } $\mathbf{2}$ & Trichorpia sp. (Ashmead) & Diapriidae & \\
\hline $\mathbf{3}$ & $\begin{array}{c}\text { Spilomicrus manii (Rajmohana } \\
\text { and Narendran) }\end{array}$ & & \\
\cline { 1 - 2 } $\mathbf{4}$ & Copterabharat varshus (Sharma) & & \\
\hline
\end{tabular}

Table.2 Per cent parasitism in fruit fly by parasitoids during mango fruiting season (Mayto August, 2018)

\begin{tabular}{|c|c|c|}
\hline \multirow{2}{*}{ Month } & \multicolumn{2}{|c|}{ Per cent parasitism } \\
\cline { 2 - 3 } & Braconidae & Diapriidae \\
\hline May & 3.05 & 1.38 \\
\hline June & 12.40 & 2.49 \\
\hline July & 13.70 & 9.54 \\
\hline August & 6.10 & 7.49 \\
\hline Pooled Mean & 8.81 & 5.22 \\
\hline $\mathbf{t}_{(\text {cal })}$ value & \multicolumn{3}{|c|}{$1.498^{*}$} \\
\hline $\mathbf{t}_{(\text {tab) }}$ value & \multicolumn{3}{|c|}{3.182} \\
\hline
\end{tabular}

*no significant difference

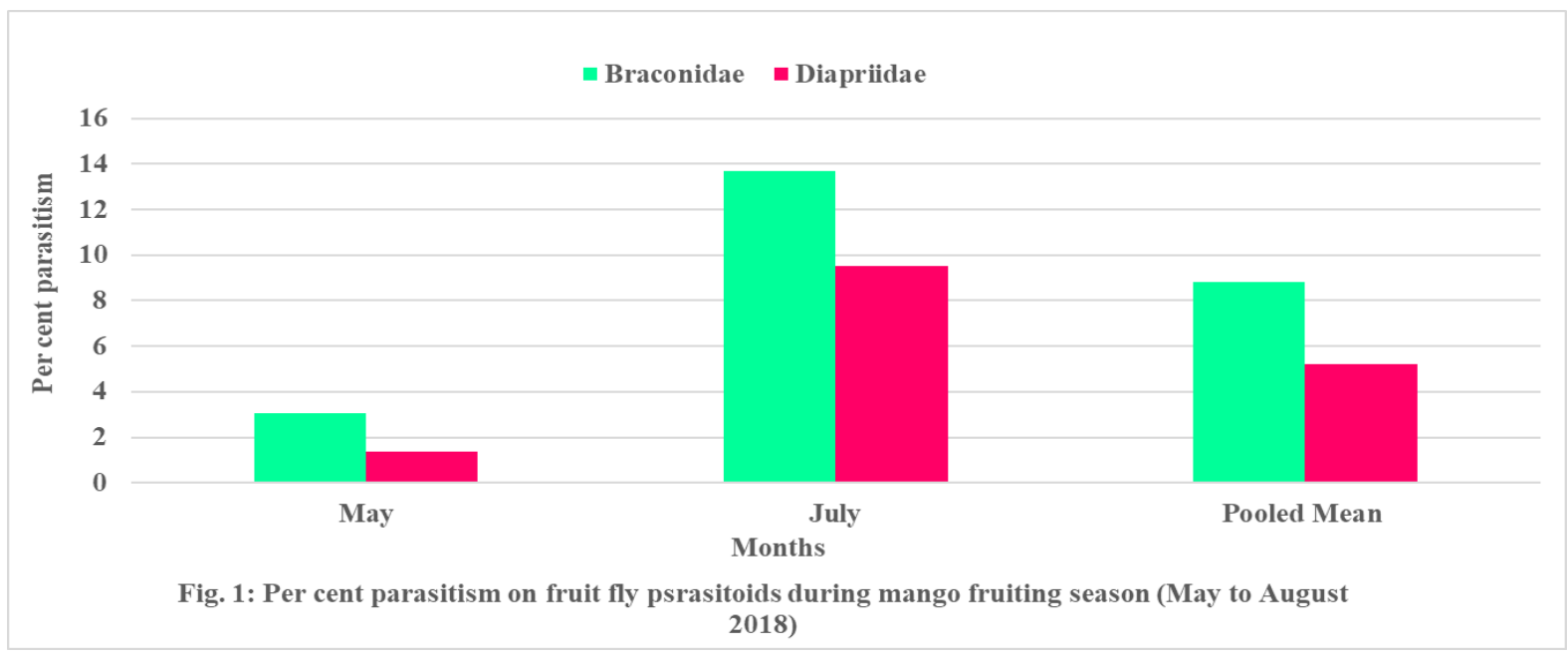


Fig.2

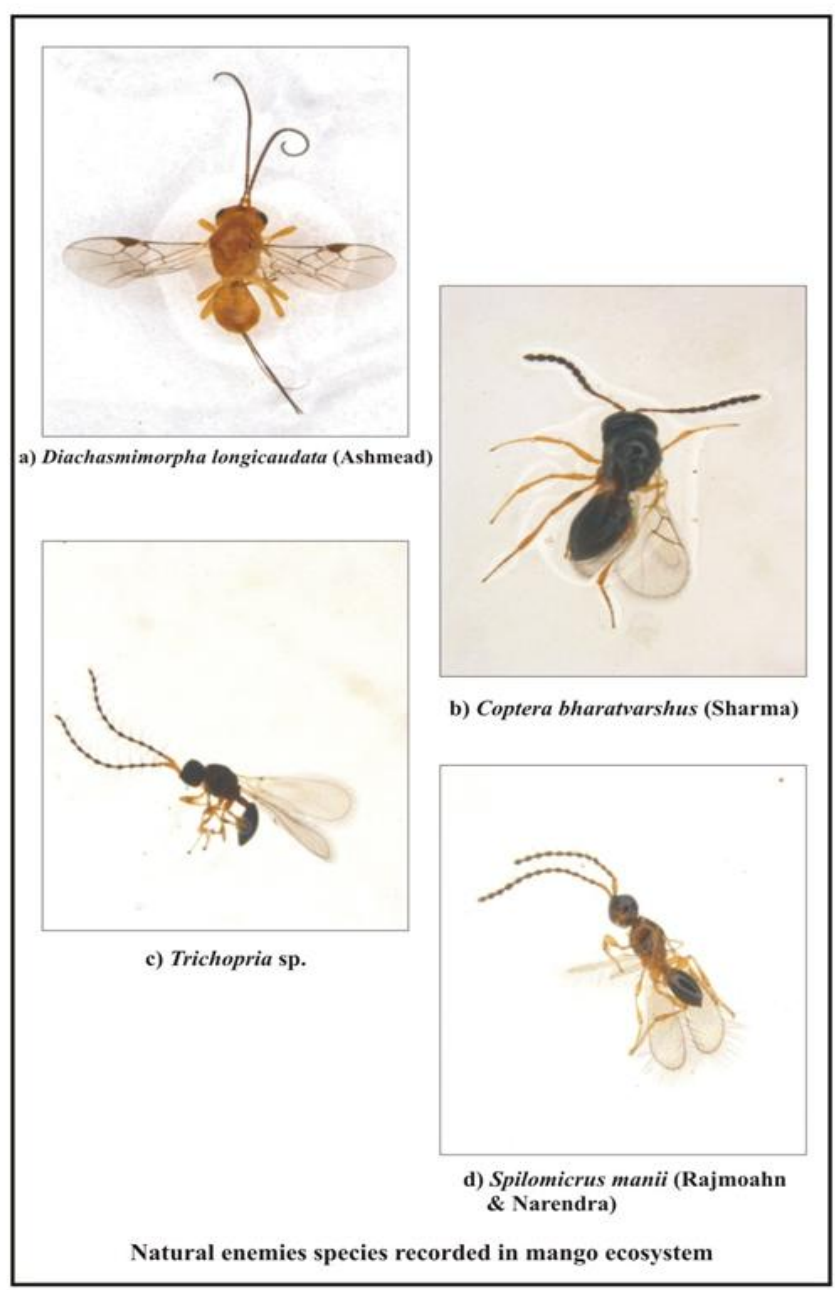

Diachasmimorpha longicaudata species complex, Trichorpia sp., Spilomicrus manii and Copterabharat varshus, were mass reared and used in augmentative releases against important fruit fly species in tropical and subtropical countries. The extent of distribution of this species complex is all over India. More studies are needed for mass rearing and augmentative releases of this parasitiods in India. Since the usage of pesticides on fruit is a nagging issue in the present context, emphasis should be given on the eco-friendly tools that could be successfully employed in the management of fruit flies, so that hazardous impact of chemicals on the environment and human health can be minimized.

\section{Acknowledgement}

The authors are thankful to Dr. Ankita Gupta (Taxonomist on Braconidae, NBAIR, Bengaluru) and Dr. Rajmohana K (Taxonomist on Diapriidae, ZSI, Kolkata) for collaborative work on natural enemies of fruit flies.

\section{References}

Aneeldev, D., Patil, R. K. and Gupta, A., 2018, Per cent parasitism of Diachasmimorpha longicaudata species complex (Hymenoptera: Braconidae) on Bractrocera spp. (Diptera: tephritidae) from North 
Karnataka. J. Exp. Zool., 21(2), 11351138.

Laskar, N., Sinha, D. K., Roy, G.,Gazmer, R. and Biswas, S., 2017, Larval-pupal parasitoid, Diachasmimorpha spp. (Hymenoptera: Braconidae) associated with melon fly, Bactrocera cucurbitae a report. Int. J. Bio-res. Env. Agril. Sci., 3(2): 545-547.

Mala, B. J., 2013, Report of a larvi-pupal parasitoid, Diachasmimorpha sp. (Hymenoptera: Braconidae) associated with fruit fly, Bactroceracaryeae (Kapoor). Pest Mgt. Hortic. Ecosyst., 19(2): 256-257.

Ovruski, S., Aluja, M., Sivinski, J. and Wharton, R., 2000, Hymenopteran parasitoids on fruit-infesting Tephritidae (Diptera) in Latin America and the southern United States: diversity, distribution, taxonomic status and their use in fruit fly biological control. Integr. Pest Mgt., 5(2): 81-107.

Singh S., (2016) Diachasmimorpha longicaudata (Ashmead): A potential parasitoid for biocontrol of fruit flies, bactrocera spp. in Punjab. Pest Mgt. Horti. Ecos., 22(1), 94-95.

Singh, S. and Kaur, G., 2016, Status of fruit flies on fruit crops in Punjab and their integrated management. Proc. Nation. Symp. on Tephritids taxonomy, Indian Inst. of Horti. Res., Bengaluru, pp. 1518.

Verghese, A., Madhura, H. S., Jayanthi, P. D.K. and Stonehouse, J. M., 2002, Fruit flies of economic significance in India, with special reference to Bactrocera dorsalis (Hendel). Proceedings of $6^{\text {th }}$ International Fruit fly Symposium held between 6-10 May 2002, Stellenbosch, South Africa, pp. 317- 324.

\section{How to cite this article:}

Ashoka, K.S. and Javaregowda. 2019. Occurrence of Natural Enemies of Fruit Flies in Mango Ecosystem. Int.J.Curr.Microbiol.App.Sci. 8(11): 1399-1403.

doi: https://doi.org/10.20546/ijcmas.2019.811.163 